\title{
Timing of Growth Faltering: A Critical Window for Healthy Growth
}

\author{
Mercedes De ONIS \\ Growth Assessment and Surveillance Unit, Department of Nutrition, World Health Organization, 20 Avenue Appia, 1211 Geneva 27, \\ Switzerland.deonism@who.int
}

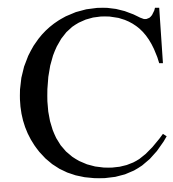

hild undernutrition remains one of the main public health challenges of the $21 \mathrm{st}$ century. Recent estimates suggest that stunting, wasting, and intrauterine growth restriction are responsible for 2.2 million deaths and $21 \%$ of disability-adjusted life-years lost among children under 5 [1]. Undernutrition also has long-term consequences, which include short adult stature, reduced intellectual development and economic productivity, and low offspring birth weight [2].

The Indian study published in this issue of Indian Pediatrics [3] examines the timing of growth faltering in under-5 children in India using the WHO Child Growth Standards. Based on national representative data, the authors conclude that about half ( $44 \%$ to $55 \%$ depending on the survey year) of growth faltering was already present at birth and that much of the growth faltering in early life in India can be attributed to faltering in height-for-age (i.e. stunting). These results, which are consistent with a recent analysis of child growth patterns worldwide [4], confirm the importance of the first two years of life as a critical window within which linear growth is most sensitive to environmentally modifiable factors. The WHO Child Growth Standards, with their robust methodology, provide an improved description of physiological growth, showing that intrauterine growth retardation is a greater problem than previously believed $[3,4]$. These findings highlight the need for prenatal and early life interventions (in the -9 to +24 months window of opportunity) to avert the growth failure that occurs during this sensitive period.
Promoting healthy growth during gestation calls for interventions to improve and safeguard maternal health and nutrition as a means to preventing intrauterine growth restriction. Once born, nutrition-dependent growth in the baby's first two years hinges upon two pillars; breastfeeding and complementary feeding. There is a large body of scientific literature on what constitutes appropriate infant and young child feeding, from exclusive breastfeeding during the first 6 months [5] to guiding principles on complementary feeding [6]. More importantly, there is ample evidence that appropriate infant feeding practices result in better growth for infants and young children in poor environments.

Since growth faltering patterns are clearly different for height-for-age and weight-for-age Z-scores, the new analyses $[3,4]$ also highlight the importance of monitoring length/height in addition to weight throughout infancy and childhood. Despite its limited use, growth velocity has considerable potential for early identification of abnormal growth and treatment responses. Apart from the inherent complexities of interpreting growth velocity, the dearth of reliable reference values has been a major impediment to gaining a better understanding of how to use growth velocities in ways that are helpful to clinicians [7]. WHO recently published standards for growth velocity (based on length, weight and head circumference) for variable intervals between birth and 24 months that fill this gap by providing a biologically robust tool reflecting age-specific changes in the rate of growth [7]. Identifying 
critical velocity pattern thresholds to screen for faltering linear growth could potentially allow early identification of children in the process of faltering, thereby making interventions more timely and effective.

The problem of stunting has early beginnings and long-term consequences. It is both a direct cause of short adult stature and sub-optimal function later in life, and a key marker of the underlying processes in early life that lead to poor growth and other adverse health outcomes. However, stunting often goes unrecognized, especially in communities where short stature is so common that it seems normal. Even among health workers, stunting generally does not receive the same attention as underweight or wasting (low weight-for-height), especially if height is not routinely measured as part of community health programs. Thus, in India, as elsewhere, early identification of linear growth faltering and an understanding of its causal role and prevention are essential for improving the effectiveness of public health programs in preventing undernutrition.

\section{REFERENCES}

1. Black RE, Allen LH, Bhutta ZA, Caulfield LE, de Onis M, Ezzati M, et al. Maternal and child undernutrition: global and regional exposure and health consequencies. Lancet. 2008;371:243-60.

2. Victora CG, Adair L, Fall C, Hallal PC, Martorell R, Richter $\mathrm{L}$, et al. Maternal and Child undernutrition: consequences for adult health and human capital. Lancet. 2008; 371:340-57.

3. Mamidi RS, Shidhaye P, Radhakrishna KV, Babu JJ, Reddy PS. Pattern of growth faltering and recovery in under-5 children in India using WHO Growth Standards A study on first and third National Family Health Survey. India Pediatr. 2011;48:855-60.

4. Victora CG, de Onis $M$, Hallal PC, Blossner M, Shrimpton R. Worldwide timing of growth faltering: revisiting implications for interventions. Pediatrics. 2010;125:3473-80.

5. WHO. The optimal duration of exclusive breastfeeding. Report of an Expert Consultation. Geneva: World Health Organization, 2002.

6. PAHO/WHO. Guiding Principles for Complementary Feeding of the Breastfed Child. Washington DC: Pan American Health Organization, 2003.

7. de Onis M, Siyam A, Borghi E, Onyango AW, Piwoz E, Garza C. Comparison of the World Health Organization growth velocity standards with existing US reference data. Pediatrics 2011; 128:e18-26. Epub 2011 Jun 27. 